\title{
A DINÂMICA INTERLOCUTIVA NA SALA DE AULA E O APRENDIZADO DE CIÊNCIAS NA EDUCAÇÃO INFANTIL
}

\author{
THE SPEAKER DYNAMICS IN THE CLASSROOM AND THE \\ SCIENCE LEARNING IN CHILD EDUCATION
}

\section{LA DINAMICA INTERLOCUTORA EN EL AULA Y EL APRENDIZAJE DE LAS CIENCIAS EN LA EDUCACIÓN INFANTIL}

\begin{abstract}
Camila Alvares*
Universidade Estadual de Londrina, Pesquisadora nos grupos de pesquisa; Universidade de Campinas, Professora na Formação Inicial

Carlos Toscano**

Universidade Estadual de Londrina, Programa de Pós-Graduação em Educação, Professor Associado
\end{abstract}

Resumo: Com este trabalho, parte de uma pesquisa mais ampla, analisou-se o desenvolvimento de uma atividade de ciências e os efeitos produzidos com os alunos de cinco e seis anos de idade de uma escola pública do interior do Paraná. Tomou-se como base teórica a perspectiva histórico-cultural, e como procedimento investigativo a abordagem microgenética. Realizaram-se observações e gravação em vídeo das aulas, que, posteriormente, foram transcritas. Os resultados apontaram uma defesa pelo ato de ensinar no contexto estudado e, por meio deste, de transmitir os conhecimentos sistematizados; entretanto, a mediação pedagógica nem sempre favoreceu a compreensão pretendida pela professora.

Palavras-chave: Educação infantil. Ensino e aprendizagem de ciências. Mediação pedagógica.

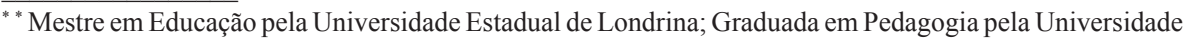
Estadual do Norte do Paraná.

** Doutor em Educação pela Universidade Metodista de Piracicaba; Mestre em Educação pela Universidade Federal de São Carlos.
} 
Abstract: With this work, part of a wider research, it was analyzed the development of a science activity and the effects produced with five and six-year old students from a public school in Paraná countryside. The historic-cultural perspective was taken as theory basis, and the micro genetics approach as investigative procedure. Observations and video recording were done, and, later, transcribed. The results showed a defense for the teaching act in the studied context and, through it, of transmitting the systemized knowledge; however, the pedagogical intermediation not always favored the comprehension intended by the teacher.

Keywords: Child education. Science teaching and learning. Pedagogical mediation.

Resumen: Este trabajo, que forma parte de una investigación más amplia analizó el desenvolvimiento de una actividad de ciencias y los efectos producidos con los estudiantes de 5/6 años de edad, en una escuela pública del interior de Paraná. Tomamos como base teórica la perspectiva histórico-cultural y como método de investigación el abordaje microgenético. Fueron hechos observaciones y video-grabaciones de las lecciones que, posteriormente, fueron transcriptas. Los resultados apuntaron una defensa por el hecho de enseñar en el contexto estudiado y, por medio de este, transmitir conocimientos sistematizados, entretanto, la mediación pedagógica ni siempre favoreció la comprensión pretendida por la profesora.

Palabras clave: Educación infantil. Enseñanza y aprendizaje de las ciencias. Mediación pedagógica.

\section{INTRODUÇÃO}

Ao se observar o percurso histórico percorrido para a constituição da educação infantil vê-se que, nem sempre, as crianças pequenas receberam a devida atenção enquanto sujeitos que necessitam de educação para se apropriarem do mundo. A preocupação, inicialmente, ocorreu a partir de um contexto específico: mulheres/ mães trabalhadoras necessitavam de um lugar para deixarem seus filhos enquanto cumpriam suas jornadas excessivas de trabalho; então, foram criadas as creches com caráter meramente assistencialista. $\mathrm{O}$ direito assegurado de receberem atendimento educacional especializado somente veio com o reconhecimento da educação infantil como dever do Estado, por meio da Constituição de 1988 (BRASIL, 1988). Portanto, trata-se de uma conquista recente no quadro da história da educação nacional.

Hoje, considerada como a primeira etapa da educação básica, a educação infantil é alvo de diversas discussões de estudiosos e pesquisadores preocupados com 
o trabalho educativo dedicado à criança pequena em seus múltiplos aspectos: físico, afetivo, psicológico, intelectual e social. Quando as atividades educacionais desenvolvidas nos centros de educação infantil e pré-escolas são bem articuladas e voltadas para a aprendizagem, estas podem possibilitar o desenvolvimento humano.

Tomando como fundamento as ideias de Vygotsky, dentro da teoria histórico-cultural, compreende-se a criança enquanto sujeito histórico, social e cultural, que estabelece relações com o mundo e com aqueles que a cercam desde o seu nascimento, dos quais recebe o aprendizado necessário acerca da linguagem, dos modos de agir, pensar e raciocinar, ocasionando o seu desenvolvimento. Em vista disso, teve-se como objetivo analisar uma atividade de ensino que desencadeou ações e discussões entre os sujeitos participantes e cujo conteúdo refere-se a animais ameaçados de extinção.

O presente texto está organizado da seguinte maneira: na próxima sessão, traz-se uma síntese da concepção da constituição humana na teoria histórico-cultural, seguida dos procedimentos metodológicos da pesquisa. Posteriormente, apresenta-se e discute-se um episódio de ensino ocorrido em sala de aula e, a seguir, finaliza-se com algumas considerações.

\section{A CONSTITUIÇÃO DA CRIANÇA ENQUANTO SUJEITO HISTÓRICO, SOCIAL E CULTURAL}

$\mathrm{Na}$ pesquisa apresentada baseia-se nos pressupostos da teoria histórico-cultural, que entende o ser humano como sujeito histórico, social e cultural, visto que explica sua constituição mediante as relações sociais nas quais está inserido desde seu nascimento. Nesse processo, ganha ênfase a linguagem.

Ao pesquisar sobre o desenvolvimento infantil, Vygotsky (2007b) esclarece que, antes de dominar o próprio corpo, a criança domina o meio em que vive com o auxílio da fala, produzindo novas relações com ele e um novo modo de organizar o próprio comportamento. De acordo com Fontana e Cruz (1997), a multiplicidade da palavra desponta na fala das crianças e indica como elas apreendem o sentido do dizer dos adultos e o relacionam com suas experiências.

De acordo com Luria (1979a, p. 81), o emprego das palavras “[...] dá à linguagem a possibilidade de tornar-se não apenas meio de comunicação, mas também o veículo mais importante do pensamento, que assegura a transição do sensorial ao racional na representação do mundo." Por conseguinte, está presente em todos os aspectos relacionados à atividade consciente do homem, reorganizando a percepção que possui do mundo externo e originando novas leis para a sua percepção. Nessa 
perspectiva, Luria (1979b) pontua que a palavra possui dois componentes: a representação material e o significado. A representação material diz respeito ao fato de que toda palavra pronunciada pelo homem representa um objeto por meio de seu som, remetendo-nos à sua respectiva imagem, mesmo que esteja ausente do campo de nossa visão. Para exemplificar, imaginemos que uma pessoa pronuncie a palavra "faca", imediatamente iremos relacioná-la a um objeto, no caso, um instrumento formado por uma lâmina cortante presa a um cabo. Já o significado vem a ser a estrutura morfológica da palavra. É a partir dele que podemos analisar os objetos, distinguir suas características essenciais e relacioná-los a uma categoria, além de ser o meio de abstração (por exemplo, a palavra relógio indica que esse objeto serve para mensurar o tempo) e de generalização (a palavra relógio indica qualquer relógio, independentemente de sua forma, cor ou tamanho).

Nas situações do cotidiano o homem emprega as palavras em conformidade com a situação em que as está usando, podendo modificar seu significado, fazendo com que desponte uma nova característica da palavra: o seu sentido. Assim, "[...] a palavra 'carvão' pode designar um pedaço de carvão de lenha, carvão de pedra, um pertence de um pintor que desenha com carvão, o mineral 'C', etc." (LURIA, 1979b, p. 22, grifo do autor). Mesmo que a palavra seja sempre a mesma, seu sentido ainda dependerá da entonação com que ela é pronunciada (LURIA, 1979b). A entonação é capaz de alterar por completo o sentido de uma palavra, por exemplo, ao pronunciarmos a palavra "burro", sem nenhuma entonação, iremos relacioná-la ao animal, no entanto, se a entonação for depreciativa, identificaremos alguém que está, em um determinado momento, sendo considerado como desprovido de inteligência. Portanto, ao pronunciar uma palavra, o homem, além de reproduzir determinado conceito direto, possibilita um grande sistema de ligações que transborda a situação do momento.

Vygotsky (2007a) lembra que qualquer aprendizado que venha a ser adquirido após o ingresso na instituição escolar possui uma história que o antecedeu. Por exemplo, antes de lidar com o estudo de aritmética na escola, a criança, provavelmente, já teria passado por experiências que envolveram quantidades, como ter de dividir em partes iguais os doces com o irmão, acrescentar mais um carrinho na coleção que, até então, era de oito. Assim, antes de entrar para a escola, a criança já é capaz de obter importantes aprendizados que orientam seu desenvolvimento, ao passar por várias experiências e ter contato com pessoas que assumem diferentes posições sociais e que, dessa forma, apresentaram o "seu mundo" para ela, por intermédio dos objetos que lhe disponibilizaram, pela forma como eles foram significados e, ainda, pelo modo como interpretaram os acontecimentos que viveram e vivem conjuntamente com ela. 
Quando o ensino é organizado de forma que o aprendizado impulsione o desenvolvimento, diversos processos internos são acionados, e isso não seria possível por outros meios. Orientado por essa tese, teoriza Vygotsky (2007a, p. 102): “[...] o ‘bom aprendizado' é unicamente aquele que se adianta ao desenvolvimento”, que está à sua frente.

Arce e Martins (2013) afirmam que, por meio dos processos de aprendizado, as funções inatas - aquelas que pertencem ao indivíduo desde o seu nascimento - são reconfiguradas. Desse modo, as funções psicológicas - memória, percepção, linguagem, pensamento, sentimento e imaginação - são estruturadas pelas interiorizações propiciadas pelos aprendizados: “Ou seja, o desenvolvimento psíquico do indivíduo ocorre apenas no processo de apropriação dos conhecimentos e procedimentos elaborados histórica e socialmente. Por conseguinte, para que haja desenvolvimento, é imprescindível que haja aprendizagem." (ARCE; MARTINS, 2013, p. 56).

Nessa perspectiva, à escola cabe um papel de destaque na promoção do desenvolvimento humano, visto que "[...] é pelo trabalho educativo que os adultos assumem um papel decisivo e organizativo junto ao desenvolvimento infantil, e da qualidade dessa interferência dependerá a qualidade do desenvolvimento." (ARCE; MARTINS, 2013, p. 57). Pela escola, a socialização do conhecimento historicamente elaborado e acumulado pela humanidade pode ser apreendida de uma forma sistemática, ou seja:

A sistematização do conhecimento implica um modo de pensar pelo qual um dado conceito é situado numa trama de outros conceitos, trama essa configurada por um sistema de relações entre níveis de generalidade. Dessa perspectiva, sistematizar é um ato de pensamento que põe em relação significados generalizados, que se organizam em termos de subordinação, coordenação e supra-ordenação. (GÓES, 2008, p. 416, grifo do autor).

Defende Góes (2008) que a significação na escola deve partir dos conhecimentos construídos na experiência os quais possibilitam sua própria sistematização ou dão base para a elaboração de novos conhecimentos. Portanto, a principal função da escola, enquanto instituição, é promover os conhecimentos sistematizados, fazendo com que as concepções embasadas nas vivências se transformem e se ampliem com vistas ao desenvolvimento científico.

Tais pressupostos põem em relevo a relação estabelecida entre os sujeitos, a interação aluno-professor, uma vez que ambos estão envolvidos com os conhecimentos sistematizados. Sob o olhar da perspectiva histórico-cultural, o processo de construção de conhecimentos se realiza com base na tríade aluno, professor e co- 
nhecimento. Nessa concepção, o aluno é considerado sujeito interativo, isto é, o qual constrói conhecimentos acerca dos objetos pela mediação do outro e concretizados por meio da linguagem, pela dialogicidade do processo (GÓES, 1997).

Dessa forma, pela dinâmica discursiva de sala de aula, há a construção coletiva dos conhecimentos. Os diálogos travados no espaço escolar aparecem como explícitos, quando existe a interação face a face, na alternância de vozes, mas também de forma implícita, por um "movimento dialógico "encoberto"” (SMOLKA, 1991, p. 17), em que o encontro das vozes ocorre pela apropriação do discurso do outro.

Ainda nesse sentido, Fontana e Cruz (1997) alertam que a sistematização pela criança não se realiza naturalmente, de forma individual, visto que ela não possui o domínio de informações e de operações intelectuais necessárias. Estas serão oferecidas e possibilitadas pela mediação do professor que, ao já dominar um amplo repertório de conhecimentos, conduzirá a criança a ter contato com diversos meios de utilização dos conceitos. " [...] cabe ao adulto, no papel de professor, possibilitar à criança o acesso aos conceitos sistematizados, procurando induzir nela formas de raciocínio e significados. Cabe à criança, no papel de aluno, realizar as atividades propostas, seguindo as indicações e explicações dadas.” (FONTANA; CRUZ, 1997, p. 111).

Em vista disso, entende-se que o professor da educação infantil não pode atuar apenas estimulando e acompanhando o desenvolvimento de seus alunos, mas, além disso, deve assumir a condução do processo educativo, começando o processo de transmissão dos conhecimentos sistematizados historicamente e enraizados na cultura.

\section{O ENSINO DE CIÊNCIAS NA EDUCAÇÃO INFANTIL}

A enorme circulação de informações em escala global e a presença de objetos tecnológicos que se intensifica cada vez mais evidenciam a necessidade e mesmo o direito ao ensino de todas as áreas de conhecimento, o que inclui também as denominadas ciências, desde o início do processo de escolarização de todos os seres humanos. Todavia, no trabalho cotidiano com os alunos da educação infantil esse aspecto fundamental nem sempre é reconhecido, pois as práticas pedagógicas que envolvem as ciências geralmente focalizam os hábitos de higiene e o reconhecimento das partes externas do corpo humano.

De acordo com Fin e Malacarne (2012), o ensino de ciências em muitas escolas brasileiras tem acontecido de modo fragmentado e maçante, isso porque o livro didático vem sendo utilizado como um manual a ser seguido de forma pronta e acabada, sem a existência de questionamentos, o que acaba por ignorar a importância 
dessa área do conhecimento para o desenvolvimento cognitivo e social dos alunos. Além disso, conforme pontuam os autores:

O que se observa é que algumas das dificuldades para o ensino de ciências, de forma geral, partem da pouca formação do professor na área das Ciências e da escassez de recursos didáticos para auxiliar no ensino desta disciplina, que, muitas vezes se limita ao livro didático e algumas poucas atividades extraclasse. (FIN; MALACARNE, 2012, p. 1).

Nas Diretrizes Curriculares Nacionais para a Educação Infantil (2010) encontra-se a consideração de que as práticas pedagógicas da educação infantil têm de oportunizar experiências as quais permitam o conhecimento de si e do mundo, o contato com diferentes linguagens, vivências éticas e estéticas levando ao conhecimento da diversidade, incentivem a curiosidade, a exploração, o questionamento e o conhecimento em relação ao mundo físico e social, ao tempo e à natureza e que proporcionem a interação, o cuidado, a preservação e o conhecimento da biodiversidade e da sustentabilidade da vida.

À vista disso, todas essas questões conduzem para a ideia de que é preciso oportunizar um ensino de ciências na educação infantil que ocorra de forma sistematizada, de modo que os alunos sejam levados a pensar cientificamente. Dessa maneira, propiciará o desenvolvimento cognitivo voltado para a compreensão da realidade e dos problemas práticos, bem como de habilidades científicas, atitudes e percepção dos fenômenos naturais por meio da linguagem e das experiências sociais.

Ignorar o trabalho com essa área de conhecimento em sala de aula significa negar a possibilidade de os alunos iniciarem o contato com essa importante parte do conhecimento humano e faz com que a criança fique limitada apenas a seus conhecimentos cotidianos, tolhendo-lhe de ter um contato mais sistematizado com essa mesma realidade.

\section{PROCEDIMENTOS METODOLÓGICOS}

Nesta pesquisa tomaram-se como referência algumas ideias da abordagem microgenética, a qual exige cuidado com os detalhes presentes em acontecimentos interativos, com vistas à análise do desempenho dos sujeitos-alvos, bem como a sua relação com aqueles que os circundam e as condições sociais em que se encontram. Essa maneira de agir propicia o entrelaçamento das dimensões culturais, históricas e semióticas. 
De acordo com a Góes (2000), essa abordagem associa o nível microgenético das interações sociais com o funcionamento dialógico-discursivo e, por isso, fundamenta-se nos pressupostos da teoria histórico-cultural, cujo precursor é Vygotsky, o qual concebe a origem das atividades humanas enraizadas nas relações intersubjetivas e na cultura. Nesse sentido, preza pelos processos e conteúdos significativos, incorporando a descrição minuciosa da interação em episódios e considerando as ações cognitivas, comunicativas e gestuais.

Trata-se de uma visão abrangente, à qual ele vincula a possibilidade de vários tipos de investigação e diretrizes metodológicas amplas que buscam atender a duas teses fundamentais: de que a gênese das funções psicológicas está nas relações sociais e de que a constituição do funcionamento humano é socialmente mediada, num curso de desenvolvimento que abrange evoluções e, sobretudo, revoluções. (GÓES, 2000, p. 12).

Assim, estudos e pesquisas que tomam como referência essa abordagem precisam ser encaminhados segundo a orientação discursiva ou enunciativa, que privilegia a perspectiva dialógica e considera a relação entre interação, discurso e conhecimento. A teoria enunciativo-discursiva de Bakhtin e Voloshinov apud (GÓES, 2000, p. 17) possibilitou focalizar a análise dos dizeres que se apresentaram no processo interlocutivo e interativo. De acordo com os autores,

[...] os processos são examinados do ponto de vista do fluxo das enunciações, numa ampliação da noção de diálogo para além dos contatos face a face, e são destacadas as práticas sociais, na consideração de condições, tais como a posição de poder dos sujeitos, a imagem dos interlocutores, as formações discursivas, os gêneros discursivos, etc.

Em razão da exigência de uma análise quanto aos detalhes indiciais, mediante uma apresentação narrativa e explicativa voltada para os discursos, foram realizadas, para a coleta de dados, observações acompanhadas de registro em um diário de campo, considerando que o pesquisador estar próximo ao objeto de estudo e observá-lo, apenas, não é suficiente, é preciso observar e registrar o que se presencia. Além disso, utilizaram-se gravações em vídeo das aulas, as quais, posteriormente, foram transcritas. A utilização de tal instrumento visa apoiar o olhar do pesquisador por possibilitar uma visualização e memória mais cuidadosa dos acontecimentos.

A coleta de dados foi realizada em uma turma de pré-escola da educação infantil, pertencente a uma escola pública de um município do interior do Paraná, composta, inicialmente, por 17 alunos, sendo 13 meninas e quatro meninos e, ao fim desta, com 15 alunos, sendo 11 meninas e quatro meninos, com idades que variam de 
cinco a seis anos, além da professora regente. Aconteceu durante o segundo semestre de 2014, três vezes por semana, por um período de quatro horas diárias, no decorrer de três meses. Iniciou em setembro e terminou em novembro, totalizando 120 horas.

Com base nessas informações, a seguir será apresentado um episódio e sua respectiva análise. Para garantir o sigilo acerca dos sujeitos, eles foram identificados com letras. Além disso, nas transcrições, as falas dos sujeitos foram grafadas em itálico e organizadas por turnos, respectivamente, enumerados. Entre colchetes e sem itálico aparece a fala do narrador, com o intuito de informar aspectos relevantes do contexto. As falas dos sujeitos encontram-se numeradas e nomeadas como turnos, com o intuito de facilitar a identificação no momento da análise.

\section{O EPISÓdIO DE ENSINO: APRESENTAÇÃO E ANÁLISE}

Esse episódio faz parte de uma sequência didática denominada De olho nos bichos, que compõe a apostila dos alunos. Episódio, aqui, é entendido como período de tempo em que um determinado assunto/conteúdo proposto desencadeou ações e discussões entre os sujeitos participantes da situação. De acordo com a autora do material apostilado (STIVAL, 2012), a unidade tem como objetivo apresentar aos alunos as características e o habitat de alguns animais, de modo a contribuir para a preservação desses seres vivos. Nesse cenário, trata-se de uma aula de aprofundamento acerca da temática, cujo conteúdo principal refere-se a animais ameaçados de extinção. A autora informa que a atividade possibilita aos alunos conhecerem alguns animais em extinção e discutirem quais os cuidados específicos que se deve ter com eles, objetivando ampliar a relação com a natureza para preservá-la. Sua realização constituiu-se das seguintes etapas: inicialmente, a professora propôs que fizessem uma leitura do alfabeto, explicando que as letras são extremamente importantes porque precisamos delas para escrever qualquer palavra, como nomes de pessoas, objetos, etc. Depois, foi mostrando letra por letra, aleatoriamente, e perguntando aos alunos de qual se tratava, bem como palavras que iniciavam com ela. Logo após, anunciou que trabalhariam em uma atividade da apostila sobre os animais que se encontram em extinção.

Durante as explicações, 13 alunos estavam na sala, alguns sentados sozinhos, outros em duplas, apesar de as mesas terem capacidade para quatro pessoas. Eles se encontravam completamente mobilizados pela atividade, prestando atenção e demonstrando interesse, além de interagirem com a professora.

Seguem as transcrições do episódio: 
(1) PROFESSORA: Primeiramente, nós vamos trabalhar uma página que nós vamos falar de alguns bichinhos que estão em extinção. Quem é que sabe o que significa essa palavrinha extinção? LU, você sabe?

(2) CA: Começa com E.

(3) PROFESSORA: Olha, esses animais... às vezes fala assim na televisão: "estes animais estão em extinção.” O LU não sabe? O KW não sabe? Ninguém sabe o que significa?

[KW balança a cabeça indicando que não]

(4) KW: Extinção, tia, é uma doença do animal.

(5) PROFESSORA: Uma doença? Não, não é uma doença.

(6) LA: É quando maltrata os animais.

(7) PROFESSORA: Oh, esta palavra... Deixa eu explicar então. Às vezes a gente ouve lá na televisão que existem animais que estão em extinção. Extinção significa que está perdendo a espécie daquele animal. Espécie quer dizer, por exemplo, o macaco, ele é uma espécie de macaco, tem o macaco, é...

(8) YH: Prego.

(9) PROFESSORA: Prego!

(10) LU: O macaco de nariz empinado.

(11) PROFESSORA: Isso! O macaco de nariz...

(12) MI: Arrebitado.

(13) PROFESSORA: Arrebitado! Dourado...

(14) LA: O gorila.

(15) PROFESSORA: Tem o gorila. Então, olha, existem várias espécies de macacos. Todos são...

(16) AP: Diferentes.

(17) PROFESSORA: Todos são macacos, mas cada um é diferente o nome do outro.

(18) LU: Tem espécie de cachorro.

(19) PROFESSORA: Tem! Olha o que o LU... Ô meu Deus, hoje está difícil!

(20) CA: Ô tia, macaco começa com $M$.

(21) PROFESSORA: Isso mesmo. Oh, olha o que que o LU disse: espécies de cachorro, de cão. E tem mesmo.

(22) LU: Vira-lata.

(23) PROFESSORA: Tem o vira-lata, tem...

(24) LU: Pitbull.

(25) PROFESSORA: Pitbull que é bravo. Tem o chow chow, acho que é assim que fala, né? 
(26) CA: O que é chow chow?

(27) PROFESSORA: É a espécie de um cãozinho. Tem... Qual mais aí, que eu não sei. (28) AP: Tem rottweiler.

(29) PROFESSORA: O rottweiler. Olha, parabéns AP. Tem mais espécies de cãozinho.

(30) YH: Mascote.

(31) PROFESSORA: Aquele que carrega...

(32) CA: Aqueles pequenininhos.

(33) PROFESSORA: Como chama os pequenininhos? Pinscher, que é aqueles cãozinhos bem pequeninho e que late ardido, né?

(34) AP: Eu tenho um.

[Os alunos falam todos juntos, não sendo possível a compreensão]

(35) PROFESSORA: Então, a espécie é assim: são todos cachorros, mas cada um é diferente do outro. Gato também, tem gatinho esses que vivem na rua, tem gato siamês...

[Os alunos falam todos juntos, não sendo possível a compreensão]

Oh, deixa só eu falar mais um pouquinho. E também, o que eu disse? Eu disse a palavra extinção. Extinção quer dizer que naqueles lugares que existem aqueles animais diferentes, aqueles bichos diferentes, existem pessoas que estão matando...

(36) YH: Coitadinhos!

(37) PROFESSORA: E, com isso, não está havendo a procriação, quer dizer, não está nascendo os animais e aí vai acabando a raça deles. E quando acaba a raça de um tipo de bicho, de animal, eles falam que este bicho está em extinção. Por quê? Porque não vai nascer, por exemplo, o cachorrinho vira-lata, se começarem a matar todos os cãozinhos vira-lata que vivem na rua, o que vai acontecer?

(38) LU: Vão morrer.

(39) YH: Vão morrerrrrr!

(40) PROFESSORA: Não vai mais existir cãozinho vira-lata, eles vão morrer e não vai mais nascer cãozinho. Então, é isso que quer dizer extinção, quando uma espécie de bicho se acaba.

(41) MA: O meu cachorro não fica na rua.

(42) PROFESSORA: E aí, eu pesquisei, e aí eu entrei, eu fui lá no computador e pesquisei lá no computador quais eram os bichos que estavam em extinção, quer dizer: estão acabando! Se os biólogos, aquelas pessoas que estudam e cuidam dos animais, se eles não prestarem bastante atenção para isso, o que vai acontecer? Alguns bichos 
vão se acabar, quer dizer, vão deixar de existir. O que quer dizer extinção? Deixar de existir. E eu tenho aqui uma listinha de animais que estão em extinção.

[A professora mostra o papel que contém a lista]

Se não cuidar, logo nós só vamos ouvir falar e só vamos ver a foto desses bichos nas revistas, nos livros, mas a gente não vai ver mais esses animais pela televisão, por quê? Porque está acabando. Olha lá, vou fazer uma listinha.

[A professora faz cinco linhas no quadro]

Oh, ai eu pesquisei lá na internet, no computador, para ver quais os bichos, os animais, que estavam em extinção. Então, oh, olha quais os bichos que estão sumindo, eu vou escrever aqui oh.

[A professora escreve "arara azul" no quadro. LU faz a leitura]

(43) LU: A-ra-ra. Arara!

(44) PROFESSORA: Leia LU.

(45) LU: Arara.

(46) PROFESSORA: Arara-azul!

(47) YH: Tem letrinha repetida.

(48) PROFESSORA: Arara-azul.

(49) CA: Tem quatro A.

(50) PROFESSORA: Mas nós estamos... Calma lá! Nós estamos falando dos bichos que, se as pessoas que tomam conta, não cuidarem, eles vão sumir. E sumir significa... (51) YH: Morrer.

(52) PROFESSORA: ...morrer e não nascer mais.

(53) LU: Arara-azul.

(54) PROFESSORA: Arara-azul é uma. Ela é toda azul, é um bicho muito bonito [...] (55) MA: É um passarinho.

(56) PROFESSORA: [...] mas que têm pessoas que, às vezes, está catando, está levando embora, está, às vezes, morrendo, está matando. E, com isso, acaba ficando em extinção.

(57) LU: No meu sítio o meu pai matou muito pintinho.

(58) PROFESSORA: Olha outro que está sumindo também.

[A professora escreve "lobo guará" no quadro]

(59) LU: Lo-bo.

(60) YH: Lo-ro! Loro!

(61) ALUNOS: Loro!

(62) LU: É lobo! Lobo!

(63) ALUNOS: Lobo! 
(64) PROFESSORA: Olha aqui, olha, o L e o O, LO. O B e o O, BO. Lobo! Lobo-guará também está em extinção.

(65) YH: E tá sumindo.

(66) PROFESSORA: Está sumindo. Esse lobo-guará, ele parece um cachorro grande, ele parece, mas não é um cachorro, ele é um lobo.

[A professora escreve "mico leão dourado" no quadro]

Vai lendo, LU!

(67) LU: Mi-co. Mico! Micó?

(68) CA: Mico!

(69) PROFESSORA: Isso CA! Mico-leão-...

(70) LA: Dourado.

(71) PROFESSORA: Dourado.

(72) LU: Mico-leão-dourado.

(73) PROFESSORA: Esse também é um animal que está sumindo...

(74) YH: Também do zoológico.

(75) PROFESSORA: Também. Está, assim, em extinção.

(76) LU: No meu sítio, o meu pai está matando muito pintinho.

(77) YH: Coitadinho.

(78) PROFESSORA: Outro que está sumindo, oh... vai lá, tenta ler.

[A professora escreve "tamanduá bandeira" no quadro]

(79) LU: Ta...

(80) LA: Tatu!

(81) ALUNOS: Tatu! Tatu! Tatu! Tatu!

(82) PROFESSORA: Não é tatu.

(83) YH: É tartaruga.

(84) ALUNOS: Tartaruga! Tartaruga!

(85) PROFESSORA: Não! Vai LU!

(86) LU: Ta-ma...

(87) LA: Tartaruga!

(88) CA: Tartaruga! Tartaruga!

(89) LU: Ela não deixa!

(90) PROFESSORA: $C A$, parou $C A$ !

(91) AP: Gato.

(92) PROFESSORA: Parou! Não, deixa só o LU. Xiii! Só o LU.

(93) LU: Ta-ma-du-á! Tamanduá!

(94) PROFESSORA: Tamanduá-...ban-dei-ra! 
[A professora escreve, depois da palavra "tamanduá", a palavra "bandeira"]

(95) LU: Tamanduá-bandeira.

(96) PROFESSORA: Tamanduá-bandeira também está sumindo.

(97) PROFESSORA: E olha, por último, olha outro bichinho que está em extinção.

[A professora escreve "onça pintada" no quadro]

(98) YH: Co...

(99) KW: Coelho!

(100) ALUNOS: Coelho! Coelho!

(101) PROFESSORA: Não, não tem nada de coelho não.

(102) LU: Oça...

(103) CA: Sapo!

(104) ALUNOS: Sapo, sapo!

(105) LU: Oça piti!

(106) PROFESSORA: Onça...

(107) YH: Pintada!

(108) PROFESSORA: Pintada!

(109) CA: E o último? Tem mais um aqui embaixo.

(110) PROFESSORA: Pintada, está escrito aqui. Então olha, esses aqui são alguns dos animais que estão em extinção...

(111) LU: Estão desaparecendo.

(112) PROFESSORA: Extinção significa estão desaparecendo. Então, oh, vou por aqui, número um, dois...

[A professora enumera os animais que estão no quadro]

(113) TODOS: ...três, quatro, cinco.

(114) LU: Cinco animais que estão desaparecendo.

(115) PROFESSORA: Eu dei... Mas, oh, só que têm mais, só que eu só falei cinco. Mas têm mais.

A seguir, tem-se a fotografia do que fora registrado no quadro: 
Fotografia 1 - Registro feito pela professora no quadro

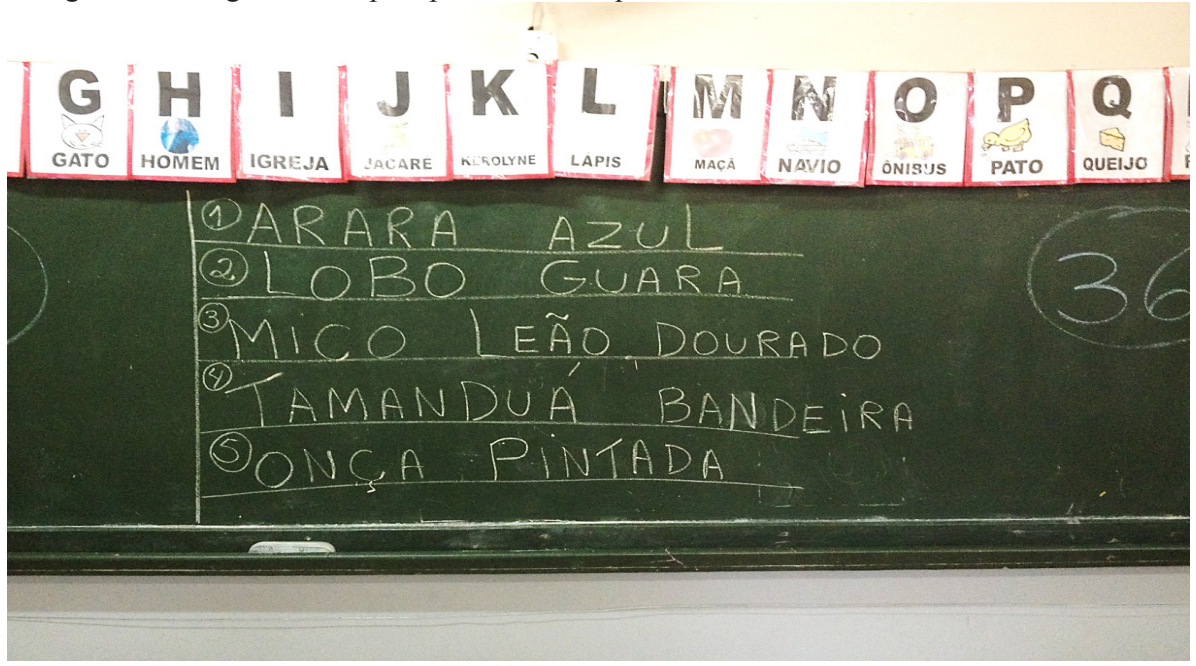

Fonte: os autores.

(116) CA: Ponha mais?

(117) PROFESSORA: A baleia, existe uma baleia que também está em extinção: baleia-franca do sul, também está em extinção.

[Os alunos falam todos juntos]

(118) LU: Eu achei que ela ia falar baleia-azul.

[Os alunos falam todos juntos, não sendo possível a compreensão]

(119) PROFESSORA: Atenção! Oh, xiiiii, pronto!

[A professora lê o enunciado da atividade]

Bicho que te quero livre. Quantos bichos, quanta beleza, quantas necessidades e quantos cuidados! Com a ajuda do seu professor, faça uma lista de nomes de animais, bichos ameaçados em extinção no Brasil.

[A professora mostra a lista no quadro]

Então, oh, nessa página 36 do livro, tem um lugarzinho aqui bem legal. E, olha, o que você vai fazer? Você vai copiar o nome desses cinco bichos aqui, cada um desses em uma linha. Você vai abrir o livro na página.

[A professora faz um círculo no quadro e dentro dele coloca o número 36]

(120) LA: 26.

(121) PROFESSORA: Não!

(122) KW: 36. Tia, 36. 
(123) PROFESSORA: 36. Oh, você vai abrir o livro na página 36 e vai copiar cada nome em uma linha.

[A professora distribui as apostilas]

A seguir, a atividade da apostila:

Figura 1 - Atividade página 36 da apostila do volume 4

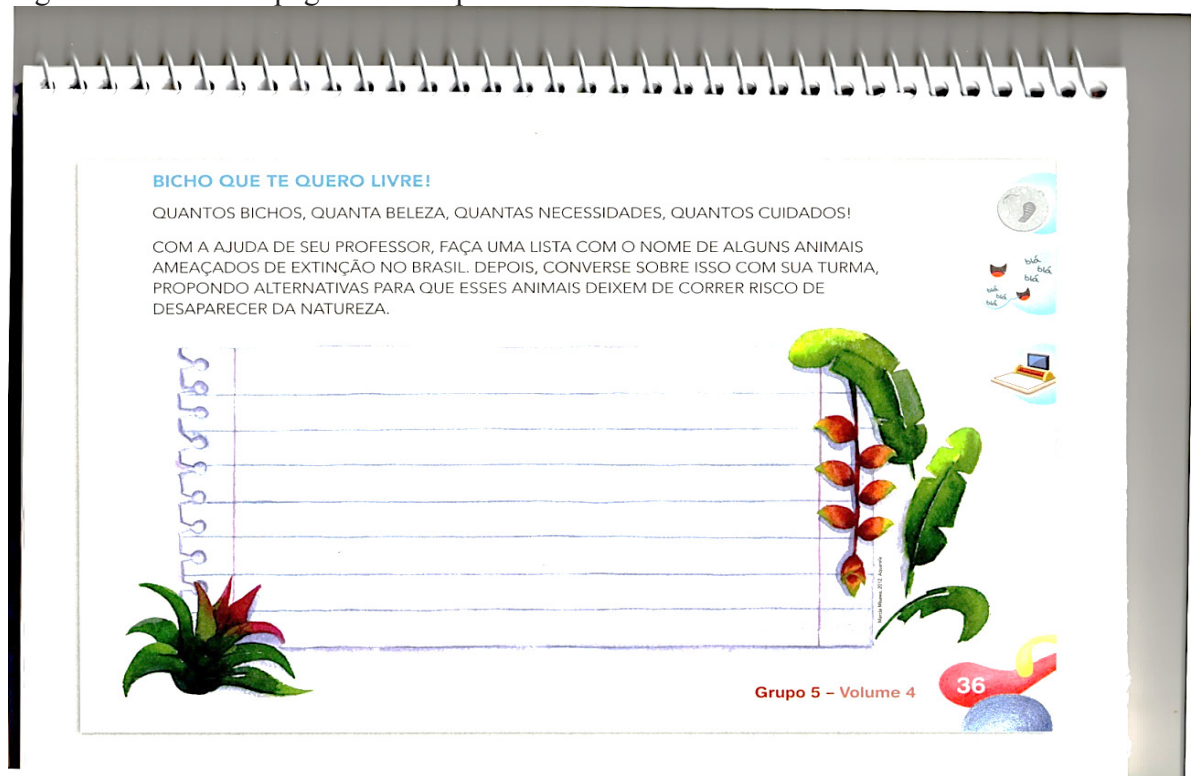

Fonte: Stival (2012).

(124) LU: Ô tia, eu já tive uma arara lá no sítio, só que o meu pai matou.

(125) PROFESSORA: Uai, por quê?

[Não foi possível compreender a resposta de LU]

Olha, eu quero bem bonitinho a cópia desses animaizinhos que estão... Existe linha que é para copiar cada um em uma linha. KA, vamos? Começa a fazer que, depois, vem outra atividade. 36, vamos! Vamos lá, trabalhando. Cada um que eu coloquei, oh, esse em uma linha, esse em uma linha, cada um em uma linha. Vamos MA, senão você vai ficar aí até amanhã.

(126) LU: Agora, eu já fiz o outro. Já tô no mico.

(127) PROFESSORA: Então vai! Eu coloquei o número que é para ninguém se perder.

(128) LU: Tamanduá-bandeira. 
[IS leva sua atividade para a professora]

(129) PROFESSORA: Esse L aqui está do lado errado, cadê o teu lápis? Olha o jeito que é... ah, está certo, ai. Certinho, parabéns!

[YH leva sua atividade para a professora]

(130) PROFESSORA: Certinho, oh parabéns. Conforme vai terminando, traz pra mim ver. Xiiii, vamos lá TH? Vai copiando devagarinho, vamos KA, vamos. Fica preocupado com o relógio aí. Vamos MI, vamos MI! Vamos lá?

[LU leva sua atividade para a professora]

Vamos ver LU. Parabéns, isso mesmo.

[AP leva sua atividade para a professora]

Arara-azul, lobo-guará, mico-leão-dourado, tamanduá-bandeira, onça-pintada. Aqui você trocou o $N$, né? Aí, copiou pelo menos. Vamos KA, vamos MI!

[LA leva sua atividade para a professora]

(131) PROFESSORA: Araraaa! Está faltando um A aqui. Arara-azul, lobo-guará, mico-leão-dourado, tamanduá-bandeira, onça-pintada, aqui você se perdeu. Aqui é o $A$, o D, não errou. Não é assim, você faz um risquinho, esse D aqui. Não, está igual, meu bem? Você fez a bolinha do mesmo lado? Presta atenção! Ai! E o A de novo. [TH leva sua atividade para a professora]

PROFESSORA: Arara-azul, esse Z... Nossa, mas olha a distância que você colocou. Lobo, tem que apagar isso aqui que está sobrando. Lobo-guará, mico-leão-douuu... aqui está errado. Segura aqui, faz o $U$ aqui, $U$, esse $U$. Doura... $O R, R$ de rato, faz aqui o $R$. $O A$, o D... não aperta demais que você vai quebrar a ponta do lápis. E o $O$. Deixa eu ver se escreveu certo? Tamanduá-bandeira, onça... certinho!

[CA leva sua atividade para a professora]

Arara-azul, lobo-guará, mico-leão-dourado, tamanduá-bandeira e onça-pintada. Xiii!

[NI leva sua atividade para a professora]

Vamos ver! Arara, está faltando um A aqui, põe o A. Deixa eu ver o que está certo, arara-azul, lobo-guará, mico-leão-dourado... Tem que continuar, sinto muito, você está lá aonde tem o quatro, eu não posso ajudar não.

[AN leva sua atividade para a professora]

Arara-azul, lobo-guará, mico-leão-dourado, tamanduá, certinho! Muita conversa!

[TH leva sua segunda atividade para a professora ver]

Certo!

(132) KA: Ai, tá demorando muito.

(133) PROFESSORA: Demora porque você está enrolando, por isso. 
(134) KW: Tia, eu terminei.

(135) PROFESSORA: Mico-leão... não, não terminou. Põe o $U$, o R, o A, o D e o $O$. Esse você terminou, vamos ver. Arara, aqui falta um $R$, põe. Põe mais perto, mais pertoooo! E o A aqui mais pertinho. Lobo-guará, tamanduá-bandeira, certinho.

(136) KW: Eu já terminei?

(137) PROFESSORA: De copiar terminou. Vamos KA!

[MA leva sua atividade para a professora]

Posso ver?

[NI leva sua atividade para a professora]

Vamos ver, arara-azul, lobo-guará, mico-leão dourado, tamanduá-bandeira, falta a última, vê se você consegue ver daqui, olha lá, o último. KA, vamos!

[NI e KA levam suas atividades para a professora] Arara-azul, lobo-guará, mico-leão-dourado, tamanduá.

[A professora arruma o que estava errado na atividade de KA]

Pronto. Conseguiu copiar né?

[KA balança a cabeça indicando que sim]

Primeiramente, serão discutidos os conceitos de espécie e extinção explicitados pela professora. A aprendizagem de novas palavras e de suas propriedades não apenas enriquece o repertório vocabular dos alunos, mas também os estimula no processo de significação/conceituação dos termos. O referido episódio abordou os animais que se encontram ameaçados de extinção, assim, logo de início, a professora explicou o termo extinção.

Mas, antes disso, buscou referências no conhecimento dos alunos, questionando-os se sabiam do que se tratava tal palavra, como se pode observar nos turnos 1 e 3. Diante de seu questionamento, houve um grande silêncio, indicando que não sabiam o significado, contudo, aconteceram algumas manifestações, como a de CA, assinalando a letra inicial da palavra (turno 2), a de KW, apontando que poderia se tratar de uma doença dos animais (turno 4), e a de LA, afirmando que se referia a maus tratos dos animais (turno 6). As falas desses alunos são tentativas de resposta e demonstram que têm pontos de partida diferentes, de acordo com a interpretação feita por eles da questão proposta. No caso de CA, ela associou a pergunta com a forma de escrever a palavra; KW elaborou uma hipótese diferente, um tipo de doença, querendo dizer, talvez, que o animal estivesse em risco; já LA, em uma linha próxima a de KW, visualizou uma situação de perigo resultante de maus tratos. Na continuidade, a professora explicou que se tratava de animais que estavam deixando de existir, entretanto, 
não buscou se aproximar das elaborações feitas pelos três alunos, exceto no turno 5 , em que negou a afirmação de KW de se tratar de uma doença. Esses momentos de levantamento de hipóteses foram extremamente ricos, todavia a professora nem sempre os aproveitou quando eles se delinearam no processo interlocutivo.

Em vez disso, tentou iniciar a explicação do conceito de extinção, mas julgou necessário explicar o conceito de espécie (turno 7). Nesse momento, percebe-se que, ao tentar explicar o significado da palavra, que não era do conhecimento dos alunos, a professora precisou se apoiar em outra palavra, cujo significado também era desconhecido deles. Tal desconhecimento pode ser percebido pela afirmação de LU, no turno 18, que se referiu às raças de cachorro para exemplificar o conceito de espécie, isto é, a tentativa pela compreensão da primeira palavra (extinção) acabou tornando ambas incompreensíveis. Essa situação, tão corriqueira em sala de aula, remete a uma consideração de Vygotsky (1998), ao abordar o ensino de conceitos e, para tanto, apoia-se em Tolstoi (1903 apud VYGOTSKY, 1998), quando afirma a necessidade de oportunizar a aquisição de novos conceitos aos alunos partindo do contexto linguístico geral, querendo, com isso, dizer que quando um aluno encontra uma palavra desconhecida em um contexto que não lhe é estranho, tem início seu processo de compreensão. Se forem fornecidas novas oportunidades, ele pode ir inserindo essa palavra e, assim, institui-se o processo de formação de um conceito.

Ao perceber o insucesso do caminho escolhido, a professora utilizou-se de exemplos que já faziam parte do conhecimento infantil, como as espécies de macaco e de cachorro, conforme se pode observar entre os turnos 7 e 35 . O exemplo de espécie de cachorros foi uma hipótese levantada por LU que a professora acolheu e trouxe para a discussão. Contudo, vê-se que espécie e raça foram colocadas como sinônimos, quando, na verdade, são duas coisas diferentes. Segundo Ferreira (2009), na biologia, a palavra espécie refere-se ao conjunto de seres semelhantes entre si e aos seus ancestrais que se entrecruzaram. Ainda de acordo com este autor, raça é o conjunto de seres que possuem caracteres somáticos semelhantes (cor da pele, olhos, etc.) e que são transmitidos por hereditariedade. Assim, vê-se que a conceituação científica de ambas as palavras não foi apresentada pela professora e discutida com os alunos.

Nesse momento, a aluna YH (turno 30) afirma que mascote também se trata de uma espécie de cachorro, quando, na verdade, é um termo utilizado para definir um animal de estimação ou um animal/pessoa utilizado para trazer sorte.

Pelos exemplos presentes no diálogo, a professora pôde retomar o conceito de extinção, afirmando que se refere àquelas espécies que estão desaparecendo, deixando de existir (turnos 35 ao 40). 
Com as discussões que se seguiram, o aluno LU recorreu à sua vivência e trouxe uma informação: que os pintinhos correm risco de desaparecer, porque são mortos por seu pai constantemente no sítio (turnos 57 e 76). Vê-se que o aluno fez uma conexão valendo-se da fala da professora, de modo, por assim dizer, literal, centrando-se no fato de que o homem mata animais. A professora não teceu consideração à sua fala, explicando a diferença e, desse modo, contribuindo com a explicitação do conceito de extinção, todavia, esta, por sua vez, não deu atenção ao comentário, ignorando tal contribuição.

Apesar da dificuldade para elucidar os conceitos, aos poucos, o conhecimento trazido pelos alunos acerca deles foi se ampliando. Isso pode ser percebido com base no turno 1, quando a professora perguntou o que significava extinção e ninguém soube responder e, no turno 111, LU já foi capaz de inferir que estavam desaparecendo.

De acordo com Luria (1979b), toda palavra possui a função de generalização, isto é, não representa um objeto único, mas uma categoria de objetos. Por exemplo, a palavra espécie que apareceu no episódio designa qualquer espécie, independente das características que a compõem. Percebe-se que, quando a palavra espécie foi pronunciada pela professora, fazendo referência ao mesmo tipo de animal, mas com algumas características diferentes, os alunos não foram capazes de fazer a ligação entre a palavra e a sua representação material de imediato, uma vez que não possuíam essa imagem. Contudo, em razão dos exemplos utilizados acerca das diferentes espécies de macaco e de cachorro, os alunos começaram a se ancorar em uma imagem conhecida, capaz de estabelecer comunicação com a professora.

Significar a palavra permite analisar um determinado objeto, distingui-lo dos demais e relacioná-lo a uma categoria. A palavra espécie advém do latim species e indica que possui relação com aparência, tipo. É um conceito essencial da Biologia, utilizado na classificação científica dos seres vivos com grandes semelhanças estruturais e funcionais. Esse conceito mostra a complexidade que uma palavra pode apresentar por conter em si diversas informações, como suas propriedades, funções e relações que possui com outros objetos.

Vygotsky (1998, p. 104) contribui, ao afirmar que:

Quando uma palavra nova é aprendida pela criança, o seu desenvolvimento mal começou: a palavra é primeiramente uma generalização do tipo mais primitivo; à medida que o intelecto da criança se desenvolve, é substituída por generalizações de um tipo cada vez mais elevado - processo este que acaba por levar à formação dos verdadeiros conceitos.

Retomando o conceito de espécie, percebe-se que a professora não discutiu esse conceito com os alunos, tomando como ideia que, para pertencer a uma espécie, 
o que a define são certos atributos ou características. Não é apenas um, mas vários. Podia, por exemplo, ter dialogado com os alunos de modo a compartilhar o aspecto central do conceito de espécie, mas não o fez, optando pelo exemplo do cachorro.

Quanto ao conceito de extinção, a professora optou por apresentá-lo verbalmente, com exemplos de espécies de animais em extinção e a apresentação da grafia de seus nomes. Partiu da ideia geral do significado de extinção, como se pode observar no turno 35, e de uma conceituação, no turno 42; depois, afirmou que extinção se referia ao risco de deixar de existir, que se encontrava em perigo. Desse modo, os alunos foram fazendo inferências e, após algumas discussões, houve um momento de construção coletiva entre alunos e professora, em que o conceito de extinção foi elaborado, isso nos turnos 111 e 112, quando afirmaram que extinção significa que estão desaparecendo. Entretanto, não foi atribuído um motivo para estar acontecendo a extinção, não houve uma elaboração que abordasse o fato de que o desaparecimento de espécies de animais se deve à ação humana contra a fauna e a flora. Novamente, vê-se que informações importantes ficaram ocultas e inacessíveis aos alunos.

Posteriormente, a professora apresentou aos alunos uma pesquisa por ela realizada acerca do nome de alguns animais que se encontram em tal situação, conforme consta no turno 42. Desse modo, escreveu no quadro o nome de cada espécie em extinção e deu espaço aos alunos para que fizessem tentativas de leitura.

Passa-se, agora, a analisar os efeitos produzidos pela proposição dessa atividade. LU foi capaz de ler quase todos os nomes sozinho, isso porque o aluno está mais adiantado em relação aos demais colegas no processo de aquisição da leitura e da escrita. Segundo a professora, é em decorrência da influência exercida pelos pais e irmãos mais velhos em casa. Por intermédio da escrita, a professora ia apresentando características mais gerais desses animais e instigava os alunos a fazerem a leitura de seus nomes, conforme consta na transcrição entre os turnos 42 a 112 .

Contudo, a apresentação desses animais ficou restrita aos seus nomes escritos no quadro e às características verbalizadas pela professora. A ausência de imagens e a não participação direta na pesquisa, para que pudesse proporcionar uma ambiência que ancorasse algumas das informações veiculadas, dificultou a sua compreensão.

Para exemplificar, tome-se o momento em que a onça-pintada é apresentada, entre os turnos 98 e 110. Como se sabe, os alunos dessa classe são provenientes de uma escola da Região Sul do Brasil e estão estudando sobre espécies em extinção, mas, em razão da localidade em que vivem, nunca tiveram contato com alguns desses animais, por exemplo, a onça-pintada, típica da região pantaneira e amazônica (Centro-Oeste e Norte do País). Assim, será somente por meio do processo de ensino 
e aprendizagem que eles irão adquirir conhecimentos referentes às características, habitat, alimentação, hábitos, entre outros, desses animais. Ou seja, não têm acesso, mas podem adquirir o conhecimento por meio da aprendizagem. Nesse sentido, pode-se afirmar que os conceitos não são absorvidos já prontos, vão sendo construídos paulatinamente pelo processo de aprendizagem.

Desse modo, trazer esses recursos para a sala de aula é um caminho a ser trilhado com vistas ao avanço da compreensão, ao melhor reconhecimento desses animais em suas características, habitat, alimentação e à identificação das ações humanas que colocam sua vida em risco, tanto do ponto de vista direto, como a caça, quanto indireto, como a eliminação das florestas, que destrói o lugar onde eles moram, cujas condições são necessárias para a sua sobrevivência.

Outro aspecto a ser analisado diz respeito ao trabalho com a escrita. A forma como o mundo se encontra socialmente organizado, em seus diferentes sistemas, proporciona uma realidade extremamente rica em que a escrita faz parte de modo preponderante. Basta olharmos ao nosso redor e veremos letras espalhadas por todos os cantos, permitindo-nos registrar e transmitir informações, por exemplo, desde as mais simples etiquetas nas prateleiras do supermercado até os grandes outdoors nas ruas e rodovias pelas quais passamos. Consequentemente, desde a mais tenra idade, somos introduzidos nesse sistema simbólico de modo diferenciado e diversificado, criado e aperfeiçoado pelo ser humano ao longo do tempo. Nos mais variados contextos sociais, nos dias de hoje temos a escrita como parte integrante da vida social e, em muitos deles, as crianças, desde muito pequenas, mantêm contato com o material escrito e buscam entendê-lo, imitando-o, brincando de ler e escrever. Esse é o caso, com graus variados, dos alunos dessa turma. No seu ambiente escolar, eles têm tido acesso sistemático à linguagem escrita e entram em contato com os conhecimentos acerca de seu funcionamento, sendo solicitados a exercitarem tais conhecimentos durante as atividades que lhes são propostas.

Segundo Fontana e Cruz (1997, p. 170), a escrita, tal como a conhecemos hoje, “[...] é uma forma de representar a palavra falada com base nos seus aspectos sonoros e nas possibilidades de uso das letras do alfabeto." Ao fazer tal representação, torna-se mais complexa do que a linguagem falada, por isso, o processo de apropriação, por parte dos alunos, é longo e difícil. "A criança apropria-se gradativamente do sistema de escrita e de suas funções sociais por meio da observação da escrita em funcionamento, das tentativas de utilizá-la que faz, pela imitação do outro, e da busca de informações sobre seus elementos e sobre seu funcionamento." (VYGOTSKY apud FONTANA; CRUZ, 1997). 
No caso do episódio aqui analisado, pode-se perceber que, embora a professora não tenha focalizado a escrita como atividade principal no início dos encaminhamentos, já que ela priorizava os conhecimentos da área de ciências e meio ambiente, passou a utilizá-los a partir de um certo momento, quando reorientou a atividade para a leitura e a cópia dos nomes dos animais em extinção selecionados por ela. Assim fazendo, não possibilitou aos alunos reconhecerem a escrita em sua função social (FIORIN, 2006), repetindo uma fórmula consagrada como tipicamente escolar, na qual para que, para quem e por que se escreve não compareceram.

É preciso considerar tais aspectos ao propor a escrita aos alunos, de modo que a percebam e compreendam como parte integrante da vida, uma vez que os gêneros escritos/discurso se fazem presentes em todas as esferas da sociedade isto é: " $\mathrm{O}$ gênero estabelece, pois, uma interlocução da linguagem com a vida social. A linguagem penetra na vida social por meio dos enunciados concretos e, ao mesmo tempo, pelos enunciados a vida se introduz na linguagem." (FIORIN, 2006, p. 61).

Assim, a apropriação da linguagem escrita não pode acontecer de forma mecânica e desprovida de sentido. É preciso chamar a atenção dos alunos para esse rico sistema de letras e números construído historicamente pela humanidade, o qual podemos considerar o maior patrimônio já produzido.

No trecho entre os turnos 42 e 110 do episódio, pode-se observar como a professora foi inserindo a escrita de novas palavras na atividade. Após escrevê-las no quadro, propôs aos alunos que copiassem os nomes dos animais em extinção no espaço destinado na apostila. À medida que eles terminavam, levavam para que ela corrigisse, a qual, por sua vez, fazia apontamentos e solicitava que alterassem o que estava errado. É possível conferir o momento da correção das atividades dos alunos nos turnos 129 e 130 .

Com base nos dois trechos apresentados, vê-se que os alunos observaram e acompanharam o processo de escrita realizado pela professora, depois, fizeram as tentativas de escrita por meio da cópia e, por fim, ela corrigiu fazendo as devidas interferências. A participação do outro, no caso a professora, foi importante como fonte de informação de como se lê e de como se escreve, uma vez que "[...] é intencional e explícita: ele proporciona à criança um contato sistemático com a escrita padronizada, que, entrecruzando-se com suas elaborações iniciais, acaba por substituí-las.” (FONTANA; CRUZ, 1997, p. 184).

Percebe-se que o objetivo da atividade apenas consistiu em cumprir a solicitação da professora de copiar a lista de animais em extinção do quadro para a apostila, segundo os turnos 119 e 123 . O processo de escrita acabou sendo reduzido ao trabalho mecânico de cópia. Nessa proposição de trabalho, predominou a ativida- 
de de codificação das palavras por meio da sua reprodução simples e comum. Ficou também evidenciado que muitas das palavras não eram do conhecimento dos alunos, os nomes eram grandes e algumas vezes compostos, ocasionando confusões e cansaço durante a escrita. A atividade mostrou-se desprovida de sentido e, consequentemente, não despertou interesse em alguns, como foi o caso de KA, que criou desculpas para não concluir a cópia, afirmando que estava demorando para conseguir finalizá-la.

Além disso, notou-se que a professora cometeu dois equívocos ao escrever os nomes dos animais em extinção no quadro, talvez por distração ou por falta de conhecimento a respeito. O primeiro refere-se a não acentuação da palavra lobo-guará. Tal palavra é considerada uma oxítona, isto é, sua acentuação tônica reside na última sílaba, por isso se deve acentuá-la com o acento agudo. O segundo, trata-se da ausência do hífen nas palavras. Segundo a nova reforma ortográfica da língua portuguesa, em vigor desde 01 de janeiro de 2009, todas as cinco palavras escritas no quadro possuem hífen, entretanto, a professora não atentou para este fato e acabou omitindo essa importante informação. Como se sabe, e já pontuado anteriormente, os alunos dessa turma estão aprendendo a linguagem escrita, sendo essencial que percebam, desde o início, não apenas o traçado das letras, mas também a composição das palavras, de modo a evitar futuros equívocos conceituais. Isso não significa que se defenda que a ortografia fosse, nesse momento, o foco do ensino, mas, considerando que a professora escreveu no quadro tais palavras, elas deveriam estar grafadas corretamente.

Outra questão a ser pensada refere-se ao fato de que, ao escrever o nome das espécies em extinção, a professora preocupou-se em organizar uma sequência, enumerando cada uma, objetivando que os alunos pudessem ter uma referência de qual animal estavam copiando e não se perdessem (turnos 112 a 114). Apesar disso, nem todos os alunos foram capazes de realizar a produção segundo as orientações dadas. Era comum esquecerem-se de copiar algumas letras, trocarem-nas por outras ou perderem-se na organização, misturando as palavras e copiando a de baixo com a de cima e vice-versa, como se pode observar, por exemplo, no trecho presente entre os turnos 131 e 137.

\section{CONSIDERAÇÕES FINAIS}

Com este estudo objetivou-se apresentar e discutir o desenvolvimento de uma atividade de ciências envolvendo uma inicial aproximação com alguns conceitos científicos pertencentes a essa área de conhecimento, os efeitos produzidos pela proposição e as formas de encaminhamento desta, com alunos de cinco e seis anos de idade, de uma escola pública do interior do Paraná. Assim, espera-se contribuir 
com as discussões acerca das práticas educativas desenvolvidas nesse nível de ensino, objetivando uma educação de qualidade que possibilite o desenvolvimento pleno de todas as capacidades dos sujeitos.

Compreendendo o ser humano como sujeito histórico, social e cultural, tomou-se como base a ideia de que ele é construído e introduzido no mundo pelas relações sociais estabelecidas desde o nascimento. Por conseguinte, é exclusivamente pela mediação dos outros que compartilham seus modos de viver, de fazer, de dizer e de pensar e, sobretudo, pela linguagem, que se é integrado aos significados produzidos e acumulados no mundo.

Nessa perspectiva, a escola assume um papel decisivo na formação humana, por propiciar o acesso sistematizado a diversos elementos da cultura, inclusive, e em especial do conhecimento científico. Dispõe-se, na educação infantil, de modo distinto, um público de crianças pequenas que está aprendendo a lidar com pessoas que lhes apresentam e reapresentam o mundo sob outro olhar; portanto, trata-se de um momento riquíssimo, porque há o desenvolvimento de um vasto repertório de habilidades e a obtenção de inúmeras informações.

Após as discussões realizadas, compreende-se a ciência como parte integrante dos conhecimentos sistematizados ao longo da história da humanidade, desse modo, a qualidade do ensino no espaço escolar é fundamental para que os alunos possam se apropriar dessa parte da cultura. A análise da realidade específica da turma observada possibilitou apreender a real dimensão e a importância do papel da educação infantil no processo de desenvolvimento de cada um.

Esse episódio, especificamente, mostrou uma defesa pelo ato de ensinar e, por meio deste, de transmitir os conhecimentos sistematizados, indo além daquele mero assistencialismo reconhecido nesse nível de ensino. Todavia, apesar de a prática docente ter sido sustentada por essa finalidade, nota-se que a mediação pedagógica nem sempre favoreceu a compreensão pretendida pela professora acerca dos conceitos científicos. Além disso, durante as explicações do conteúdo e da atividade, as significações expostas pelos dizeres dos alunos não foram devidamente incorporadas ao processo dialógico, principalmente quando os dizeres não estavam de acordo com o esperado pela professora. Portanto, houve certa priorização pelo comunicado de certas informações e conceitos científicos em detrimento da consideração da possibilidade de uma elaboração conjunta a partir daquilo que era compartilhado pelos alunos na dinâmica interlocutiva instaurada com a proposição da referida atividade de ensino.

Nessa perspectiva, considera-se a necessidade de se instaurar uma mediação pedagógica que busque incorporar a reflexão sobre os dizeres que se apresentam no 
processo, de modo que estes sejam explicitados em sua significação inicial e se tornem objeto de análise progressiva, com o intuito de avançar na compreensão daquilo que está sendo objeto de estudo e que tem como referência os conceitos científicos. Isso não significa que o percurso dessa apropriação seja linear e imediato, entretanto, somente desse modo ele poderá resultar em algo produtivo e significativo pelos sujeitos.

\section{REFERÊNCIAS}

ARCE, A.; MARTINS, L. M. A educação infantil e o ensino fundamental de nove anos. In: ARCE, A.; MARTINS, L. M. (Org.). Quem tem medo de ensinar na educação infantil? Em defesa do ato de ensinar. 3. ed. Campinas: Alínea, 2013. cap. 2, p. 39-65.

BRASIL. Constituição. República Federativa do Brasil de 1988. Brasília, DF: Senado Federal, 1988. Disponível em: < http://www.planalto.gov.br/ccivil_03/constituicao/constituicao.htm>. Acesso em: 24 ago. 2015.

BRASIL. Diretrizes curriculares nacionais para a educação infantil. Brasília, DF: MEC: SEB, 2010.

FERREIRA, A. B. de H. Novo dicionário Aurélio da língua portuguesa. 4. ed. Curitiba: Positivo, 2009.

FIN, A. S. de; MALACARNE, V. A concepção do ensino de ciências na educação infantil e as suas implicações na formação do pensamento científico no decorrer do processo educacional. In: SEMINÁRIO DE PESQUISA DO PPE, 11., 2012, Maringá. Anais... Maringá, 2012. Disponível em: <http://www.ppe.uem.br/publicacoes/ seminario_ppe_2012/trabalhos/co_02/030.pdf>.Acesso em: 22 ago. 2016.

FIORIN, J. L. Os gêneros do discurso. In: FIORIN, J. L. Introdução ao pensamento de Bakhtin. São Paulo: Ática, 2006.

FONTANA, R. A. C.; CRUZ, M. N. da. Psicologia e trabalho pedagógico. São Paulo: Atual, 1997.

GÓES, M. C. R. de. A abordagem microgenética na matriz histórico-cultural: Uma perspectiva para o estudo da constituição da subjetividade. Cadernos Cedes, ano 20, n. 50, p. 9-25, abr. 2000.

GÓES, M. C. R. de. A aprendizagem e o ensino fecundo: apontamentos na perspectiva histórico-cultural. In: ENCONTRO NACIONAL DE DIDÁTICA E PRÁTICA DE ENSINO, 14., 2008, Porto Alegre. Anais... Porto Alegre: PUCRS, 2008. 
GÓES, M. C. R. de. As relações intersubjetivas na construção de conhecimentos. In: GÓES, M. C. R. de; SMOLKA, A. L. B. A significação nos espaços educacionais: interação social e subjetivação. Campinas: Papirus, 1997.

LURIA, Alexander Romanovich. A atividade consciente do homem e suas raízes histórico-sociais. In: LURIA, Alexander Romanovich. Curso de psicologia geral: Introdução evolucionista à psicologia. Tradução de P. Bezerra. Rio de Janeiro: Civilização Brasileira, 1979a. v. 1. cap. 3.

LURIA, Alexander Romanovich. A palavra e o conceito. In: LURIA, Alexander Romanovich. Curso de psicologia geral: linguagem e pensamento. Tradução de P. Bezerra. Rio de Janeiro: Civilização Brasileira, 1979b. v. 4. cap. 2.

SMOLKA, A. L. B. Múltiplas vozes na sala de aula: aspectos da construção coletiva do conhecimento na escola. Trab. Ling. Apl., Campinas, p. 15-28, jul./dez. 1991.

STIVAL, S. Educação infantil: grupo 5: integrado por eixos. Curitiba: Positivo, 2012. (Exemplar do professor, v. 4).

VYGOTSKY, L. S. Interação entre aprendizado e desenvolvimento. In:

VYGOTSKY, L. S. A formação social da mente: o desenvolvimento dos processos psicológicos superiores. 7. ed. Tradução José Cipolla Neto, Luis Silveira Menna Barreto e Solange Castro Afeche. São Paulo: Martins Fontes, 2007a.

VYGOTSKY, L. S. O desenvolvimento dos conceitos científicos na infância. In: VYGOTSKY, L. S. Pensamento e linguagem. 2. ed. São Paulo: Martins Fontes, 1998.

VYGOTSKY, L. S. O instrumento e o símbolo no desenvolvimento da criança. In: VYGOTSKY, L. S. A formação social da mente: o desenvolvimento dos processos psicológicos superiores. 7. ed. José Cipolla Neto, Luis Silveira Menna Barreto e Solange Castro Afeche. São Paulo: Martins Fontes, 2007b.

Recebido em: 14 de abril de 2016 Aceito em: 02 de setembro de 2016

Endereço para correspondência: Rodovia Celso Garcia Cid, Km 380, s/n, Campus Universitário, 86057-970, Londrina, Paraná, Brasil; mila.alvares@hotmail.com 
